\title{
GMR
}

\section{Biological changes of Enterococcus faecalis in the viable but nonculturable state}

\author{
J. E, Y.T. Jiang, P.F. Yan and J.P. Liang
}

Department of Endodontics and Operative Dentistry, Ninth People's Hospital, School of Medicine, Shanghai Jiao Tong University, Shanghai, China

Corresponding author: J.P. Liang

E-mail: liangjp_shanghai@126.com

Genet. Mol. Res. 14 (4): 14790-14801 (2015)

Received June 18, 2015

Accepted September 9, 2015

Published November 18, 2015

DOI http://dx.doi.org/10.4238/2015.November.18.44

\begin{abstract}
Enterococcus faecalis may enter a viable but nonculturable (VBNC) state under adverse conditions. E. faecalis, the major bacterial species present in failed root canal treatments, is thought to survive after endodontic treatment by entering a VBNC state. In this study, we characterized the VBNC state of E. faecalis. We designed 3 different protocols to successfully induce the VBNC state. Approximately one-third of bacteria entered a VBNC state after 15-30 days, and all remained viable for at least 2 months. The morphology, glycometabolism, and adhesion capabilities of VBNC cells differed from those of $E$. faecalis during the exponential growth phase. Specifically, VBNC E. faecalis cells could not decompose lactose, D-mannitol, or D-sorbitol, although they were able to metabolize sucrose. Transmission electron microscopy showed that the morphology of the VBNC E. faecalis cells changed significantly; the cytoplasmic matrix was unevenly condensed and the overall morphology of the cells became irregular, but the cell membranes remained intact. Although the adhesion ability of the bacteria decreased, VBNC E. faecalis could still adhere to collagen fiber type
\end{abstract}


I and tooth dentine. The persistence of this adhesion ability may be important in the virulence of VBNC E. faecalis.

Key words: Adhesion ability; Enterococcus faecalis; Morphology; Viable but nonculturable

\section{INTRODUCTION}

Root canal treatment (RCT), which is the classical treatment for endodontic infections, can seal and separate the root canal system from sources of bacterial infection. However, the failure rate of RCT is as high as 10-15\% (Smith et al., 1993). Moreover, the risk of repeat infection in teeth with failed RCT is higher than in teeth with successful RCT (Molander et al., 1998; Sundqvist et al., 1998). Enterococcus faecalis constitutes a small percentage of the microbial species isolated from the root canals of teeth with necrotic dental pulps. However, E. faecalis is the most common species isolated from secondary endodontic infections. Polymerase chain reaction (PCR) detection identified E. faecalis in 82 and $76 \%$ of primary and secondary root canal infections, respectively. In contrast, E. faecalis was cultured from only $4 \%$ of untreated necrotic pulps (primary infections) and from $42 \%$ of root-treated canals (secondary infections) using traditional culture methods (Gomes et al., 2006). These findings demonstrate that E. faecalis is likely involved in the failure of endodontic treatment and that the bacteria in root-treated canals cannot be quantitatively detected using traditional culture methods. E. faecalis is the major species thought to cause endodontic treatment failure and refractory periapical periodontitis, and it is detected in $50-70 \%$ of these cases (Peciuliene et al., 2000; Pinheiro et al., 2003). The treated root canal is a unique niche that is low in nutrients and is comparatively well-sealed. E. faecalis can survive in this environment and induce root canal infection. The persistence of $E$. faecalis is thought to result from its ability to enter a viable but nonculturable (VBNC) state, which was first described for E. faecalis by Lleò et al. (1998), but the mechanism is unknown.

The VBNC state is a stress-response mechanism triggered by adverse growth conditions. When bacteria enter the VBNC state, they lose their ability to form colonies on culture media (Lleò et al., 1998), but continue to express antigen components (Smith and Oliver, 2006) and virulence factors (Pruzzo et al., 2002). VBNC bacteria may be able to resume cell division and promote disease transmission and persistence when permissive conditions are restored (Lleò et al., 2001). VBNC E. faecalis cells appear to maintain their viability, pathogenicity, and other biological characteristics such as gene expression (Lleò et al., 2000) and metabolic activity (Lleò et al., 1998). However, there are a number of differences in the biology, biochemistry, and genetics of VBNC cells and exponentially dividing cells, including changes in morphology, metabolism, and gene expression (Oliver, 2005) which help VBNC bacteria survive under adverse conditions; however, there are few reports in the current literature.

In this study, we successfully induced a VBNC state in E. faecalis cells using 3 different protocols and investigated the characteristics of VBNC cells, including their morphology, metabolic profile, and adherence properties. 


\section{MATERIAL AND METHODS}

\section{Bacteriological strains and growth conditions}

The E. faecalis laboratory strain ATCC33186 was grown in trypticase soy yeast extract broth. Cell growth was monitored using a spectrophotometer at a wavelength of $600 \mathrm{~nm}$ $\left(\mathrm{OD}_{600}\right)$. Colony-forming unit (CFU) counts of culturable bacteria were performed by seeding samples in duplicate on trypticase soy yeast agar (TSA) plates.

\section{Induction of VBNC state}

Three different laboratory growth conditions were used, including an oligotrophic microenvironment that was prepared by adding sterile distilled water to a flask. The other 2 microenvironments consisted of alkaline medium prepared using sterilized sodium buffers at $\mathrm{pH} 9$ and 11. For each condition, $600 \mathrm{~mL}$ E. faecalis culture in the mid-exponential growth phase $\left(\mathrm{OD}_{600} \approx 0.7\right)$ (Pfeffer et al., 2006) was centrifuged at $4500 \mathrm{~g}$ for $15 \mathrm{~min}$. The cell pellet was washed twice in phosphate-buffered saline. The washed cells were transferred to 3 $500-\mathrm{mL}$ flasks at a final density of $10^{7}$ cells $/ \mathrm{mL}$ and incubated at $37^{\circ} \mathrm{C}$. The cultures were monitored by CFU counts every 3 days from triplicate samples. A population was considered to be in the VBNC state when no colonies were detected after $10 \mathrm{~mL}$ cell culture seeded on solid culture medium.

\section{Viability tests}

The viability of the inoculated E. faecalis cells was tested by reverse transcriptionPCR by using a primer pair specific for the E. faecalis penicillin-binding protein 5 gene, which encodes a protein involved in peptidoglycan synthesis (Robbi et al., 1996). Two primers within the gene (forward, 5'-CATGCGCAATTAATCGG-3'; reverse, 5'-CATAGCCTGTCGC AAAAC-3') were used. Extracted RNA was also used as template when performing the PCR procedure to rule out DNA contamination. The size of the expected amplification product was 444 bp. In addition, cell viability was measured using a Live/Dead kit (Invitrogen, Carlsbad, CA, USA). This kit utilizes a mixture of the green-fluorescent nucleic acid stain SYTO9 and the red-fluorescent nucleic acid stain, propidium iodide, to evaluate cell membrane integrity (Roth et al., 1997). When used alone, the SYTO9 stain generally labels all bacteria in a population, including those with intact membranes and those with damaged membranes. In contrast, propidium iodide penetrates only bacteria with damaged membranes, reducing the SYTO9 stain fluorescence when both dyes are present. Therefore, in this assay, live cells appeared to be green, while dead cells appeared to be red under fluorescent microscopy. Reverse transcription-PCR and fluorescent staining were performed every 10 days until no culturable cells were observed.

\section{Resuscitation of VBNC E. faecalis}

The nonculturable $E$. faecalis resumed division and were monitored on TSA plates after growth in trypticase soy yeast extract broth $-0.5 \%$ glucose overnight at $37^{\circ} \mathrm{C}$ as previously described by Lleò et al. (2001). 


\section{Acid production ability and biochemical identification}

The $\mathrm{pH}$ value was monitored every 3 days after the bacteria were inoculated. Pure cultures and colonies in the mid-exponential phase E. faecalis (cultured for approximately 24 $\left.\mathrm{h}, \mathrm{OD}_{600 \mathrm{~nm}} \approx 0.7\right)$ and VBNC E. faecalis cells were selected for biochemical identification using the Rapid ID 32 Strep (BioMérieux, Marcy l'Etoile, France). The ATB Miniapi Software (BioMérieux) was used to automatically read the ID 32 tests. Lactose, maltose, mannitol, sorbitol, and urease were used as biochemical substrates. The Rapid ID 32 Strep is a qualitative experiment rather than a quantitative test.

\section{Transmission electron microscopy (TEM)}

Cells in the VBNC state were centrifuged at $2500 \mathrm{~g}$ for $15 \mathrm{~min}$ and the cell pellets, which were approximately the size of a grain of rice, were fixed with $2 \%(\mathrm{v} / \mathrm{v})$ glutaraldehyde for at least $2 \mathrm{~h}$. The fixed pellets were washed twice with phosphate-buffered saline for $10 \mathrm{~min}$ each and post-fixed with $1 \%$ osmium tetraoxide for $1 \mathrm{~h}$. The cells were washed twice with phosphate-buffered saline and dehydrated with successive ethanol washes (30-100\%). Each dehydration step was performed for $10 \mathrm{~min}$ at $4^{\circ} \mathrm{C}$. Two 10 -min washes with propylene oxide were carried out, and the preparations were embedded in a mixture $(\mathrm{v} / \mathrm{v})$ of propylene oxide and embedded in 618-araldite epoxy resin for $2 \mathrm{~h}$. The mixture was removed and replaced with $100 \%$ resin for $6 \mathrm{~h}$. Resin polymerization was performed for $48 \mathrm{~h}$ at $60^{\circ} \mathrm{C}$. Samples were prepared for TEM using an LKB ultramicrotome. Sections that were $50 \mathrm{~nm}$ in thickness were stained using lead citrate and visualized using a Philips CM-120 TEM (Amsterdam, Netherlands). Cells in the exponential growth phase were also analyzed to compare the differences between the 2 phases.

\section{Scanning electron microscopy}

The ability of cells to adhere to collagen or dentine was tested by adding bacteria in the VBNC state to dishes containing sterilized collagen fibers or pieces of dentine. The dishes were incubated in an anaerobic culture chamber at $37^{\circ} \mathrm{C}$ for $48 \mathrm{~h}$. Cells in the exponential growth phase were also cultured as a positive control. We used shaker $(180 \mathrm{rpm})$ during the incubation period to remove the influence of dead cells mixed with the VBNC cells. After incubation, the dishes were washed twice with sterile distilled water to remove nonadherent bacteria. The collagen fibers and dentine pieces were fixed with $2 \%(\mathrm{v} / \mathrm{v})$ glutaraldehyde for $2 \mathrm{~h}$ and washed twice with sterile distilled water. Next, the collagen fibers and dentine pieces were snap-frozen at $-80^{\circ} \mathrm{C}$ for $15 \mathrm{~min}$. The samples were dried in a vacuum freeze dryer (Labconco, Kansas City, MO, USA), gold-coated, and examined by scanning electron microscopy (S-3000N; Hitachi, Tokyo, Japan).

\section{RESULTS}

\section{Evaluation of time to enter VBNC state by $E$. faecalis cells in different microenvironments}

The 3 different laboratory microenvironments were inoculated in an anaerobic envi- 
ronment at $37^{\circ} \mathrm{C}$. Every 3 days, samples were withdrawn aseptically from the microenvironments and culturable cell numbers were evaluated by determining the CFU of diluted samples on TSA plates. When the CFU count was close to zero, $10-\mathrm{mL}$ samples were filtered using $0.22-\mu \mathrm{m}$ filters (Millipore, Billerica, MA, USA), and the filters were placed face-up on the TSA plates. The bacteria were considered to have reached the VBNC state when the number of culturable cells was less than 0.1 cells $/ \mathrm{mL}$.

As shown in Figure 1, the E. faecalis in group 1 became nonculturable within 30 days, but the same bacteria grown in the alkaline microenvironments required only 15 days to reach the nonculturable state. Live/dead staining showed that for the 3 tested conditions, 39, 36, and $22 \%$ of the bacteria were still alive after 1 month. In addition, reverse transcription-PCR demonstrated that cells cultured in the sterile distilled water expressed penicillin-binding protein 5 gene continuously for 3 months, but the cells cultured in the sodium buffer, $\mathrm{pH} 9$ and 11, expressed penicillin-binding protein 5 gene for only 1.5 months.

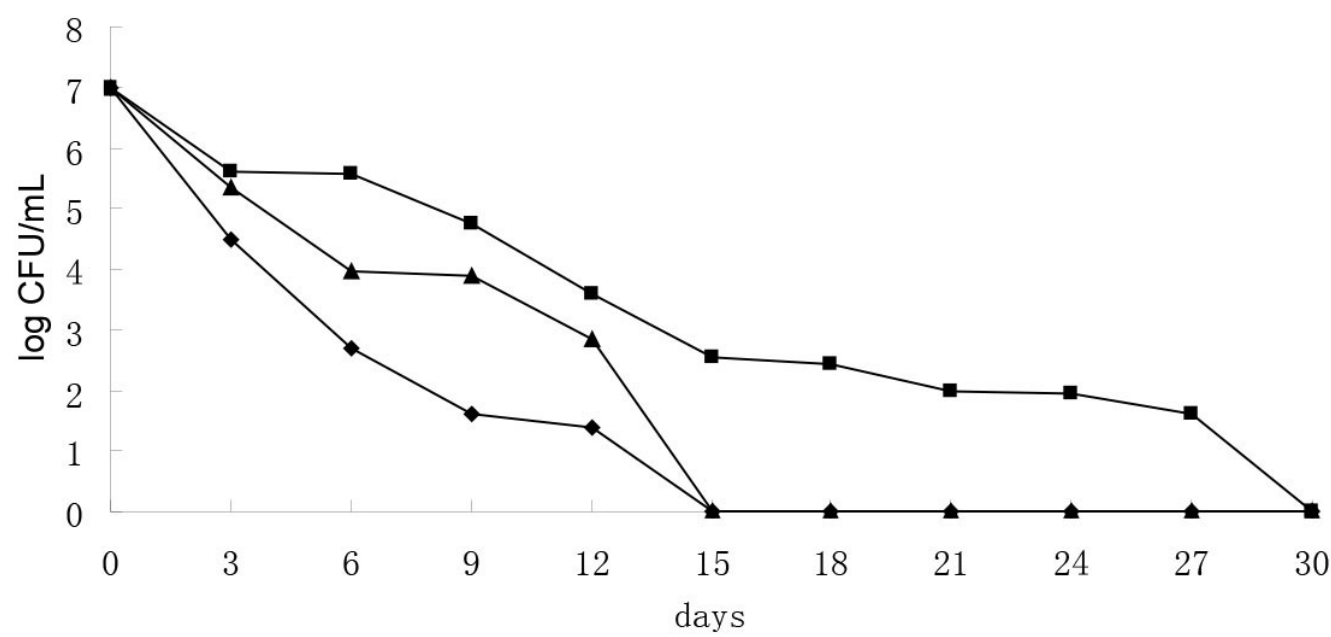

Figure 1. Decline of Enterococcus faecalis when incubated at $37^{\circ} \mathrm{C}$ in sterile distilled water (squares), sterilized sodium buffer, $\mathrm{pH} 9$ (triangles), and sodium buffer, $\mathrm{pH} 11$ (lozenges). Each point is the mean of triplicate samples. The error bars were removed for clarity.

\section{Acid production ability and glycometabolism observed in VBNC E. faecalis cells}

The $\mathrm{pH}$ values of the samples were measured every 3 days from the beginning of the inoculation. The $\mathrm{pH}$ of the samples under all 3 conditions decreased from 8.05 to $6.06,9.68$ to 8.30 , and 10.74 to 9.82 in the sterile distilled water and from $\mathrm{pH} 9$ and 11 in sodium buffer conditions, respectively (Table 1). The decrease in $\mathrm{pH}$ was more evident in the distilled water than in the sodium buffer, indicating that the alkaline condition influenced the ability of the bacteria to produce acids although the alkaline condition was buffered. However, whether this change resulted from the alkaline condition requires further analysis.

Rapid ID 32 Strep tests were placed in a $37^{\circ} \mathrm{C}$ environment for $4 \mathrm{~h}$, and the results were read automatically using the Mini API Software. The VBNC E. faecalis could metabolize sucrose similarly to the rate of exponentially growth E. faecalis cells, but the VBNC cells could not decompose lactose, D-mannitol, or D-sorbitol. 
Table 1. pH value of Enterococcus faecalis after incubation for 1 month.

\begin{tabular}{|c|c|c|c|c|c|c|c|c|c|}
\hline & 0 day $^{1}$ & 3 days & 6 days & 9 days & 12 days & 15 days & 18 days & 21 days & 24 days \\
\hline Sterilized distilled water & 8.05 & 7.65 & 7.46 & 6.64 & 6.30 & 6.14 & 6.09 & 6.08 & 6.06 \\
\hline Sterilized sodium buffer group 1 & 9.68 & 9.36 & 9.22 & 9.25 & 8.90 & 8.70 & 8.80 & 8.40 & 8.30 \\
\hline Sterilized sodium buffer group 2 & 10.74 & 10.58 & 10.52 & 10.5 & 10.45 & 10.39 & 10.24 & 10.03 & 9.82 \\
\hline
\end{tabular}

E. faecalis cells incubated in sterilized distilled water, sterilized sodium buffer, pH 9, and sodium buffer, pH 11.

\section{Morphological changes in VBNC E. faecalis cells}

TEM of the normal cells showed that the E. faecalis were mostly coccoid, with an average diameter of 2.3-2.8 $\mu \mathrm{m}$ (Figure 2a). The cell membranes were intact, cytoplasmic staining was dark, and a number of extracellular granular secretions were observed.

The VBNC cells exhibited several changes compared with normal cells. The average diameter of the coccoid cells was 3.0-4.5 $\mu \mathrm{m}$ (Figure 2b, c, and d), which was much larger than that of normal cells. The membranes appeared to be intact, but the cytoplasm was irregular compressed and the staining was lighter. The cell cytoplasm was unevenly condensed, and there were significant gaps between the cytoplasmic membrane and the cell wall. Membrane curling was observed in some of the cells, which was associated with irregular cell morphology. Some cells appeared to have vacuolar degeneration and a loose uneven cytoplasmic matrix.

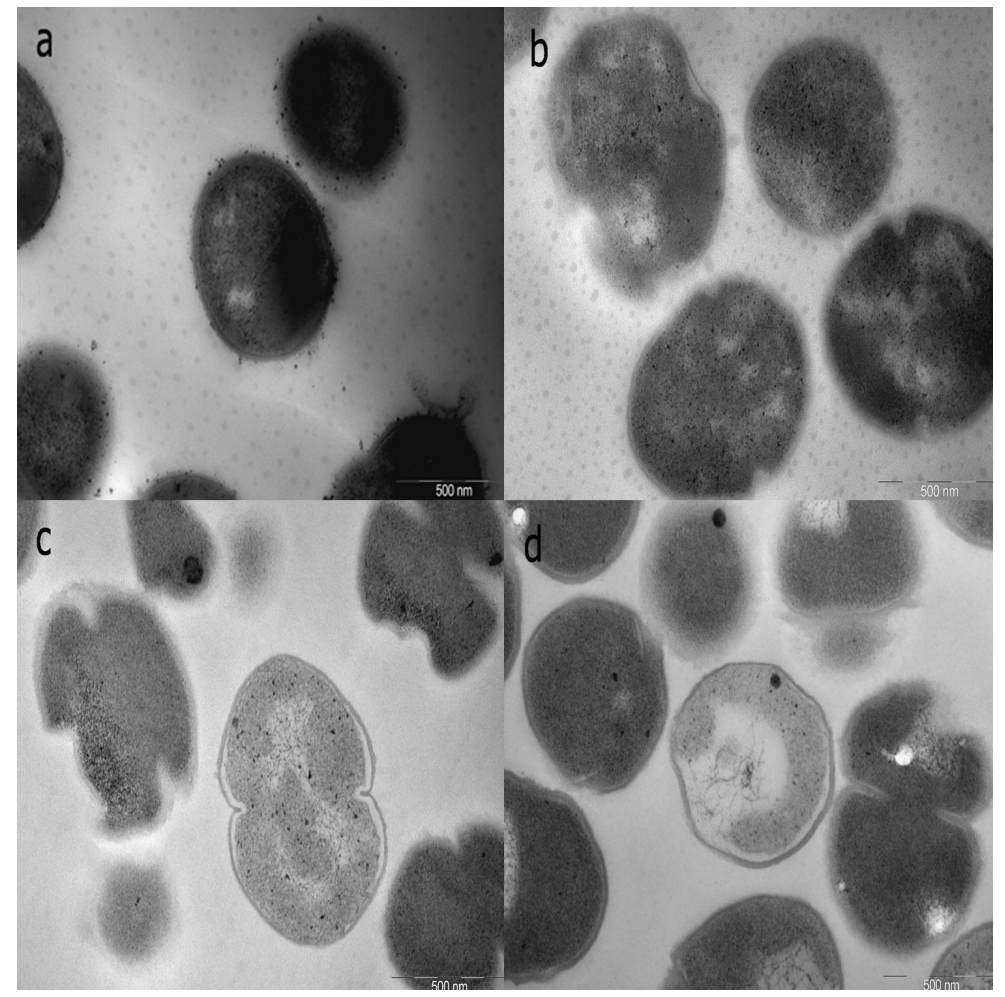

Figure 2. Morphological changes of the VBNC Enterococcus faecalis analyzed using TEM $(65,000 \mathrm{X})$. Normal cells (a) and VBNC cells (b, c, and d). b, c, and d are corresponding E. faecalis cells incubated in sterile distilled water, sterile sodium buffer, $\mathrm{pH}$, and sodium buffer, $\mathrm{pH} 11$, respectively. 


\section{Adhesion ability of $E$. faecalis cells}

Scanning electron microscopy showed that both normal and VBNC E. faecalis cells had a coccoid shape (Figures 3 and 4). Significantly fewer VBNC cells adhered to the collagen or dentine compared with the normal cells, particularly when the cells were cultured in sodium buffer, $\mathrm{pH}$ 11. A subset of VBNC cells appeared to have changes in their shape when adhered to dentine, and they were not able to enter the dentine tubes. In contrast, normal E. faecalis cells entered the dentine tubes and retained their coccoid shape.

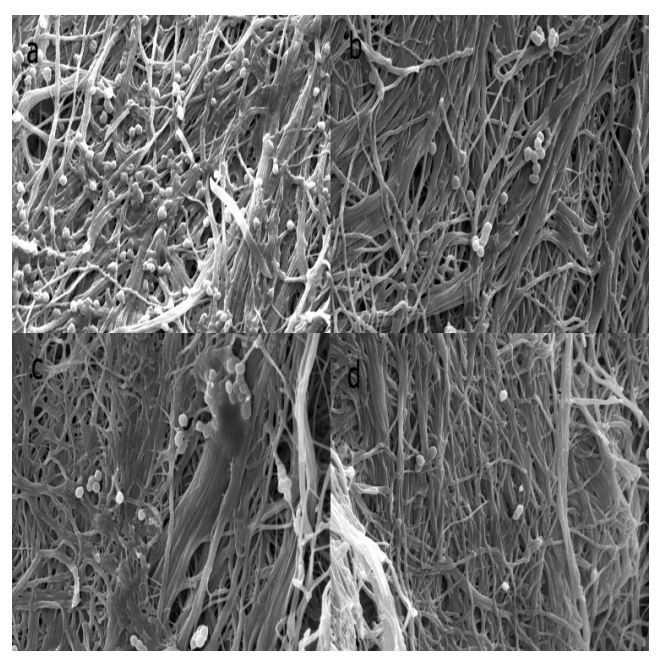

Figure 3. Scanning electron micrograph of Enterococcus faecalis adhered to collagen fiber (5,000X). Exponential phase cells (a), VBNC cells in sterile distilled water (b), VBNC cells in sodium buffer (c and d) with collagen fiber incubated at $37^{\circ} \mathrm{C}$ for $48 \mathrm{~h}$.

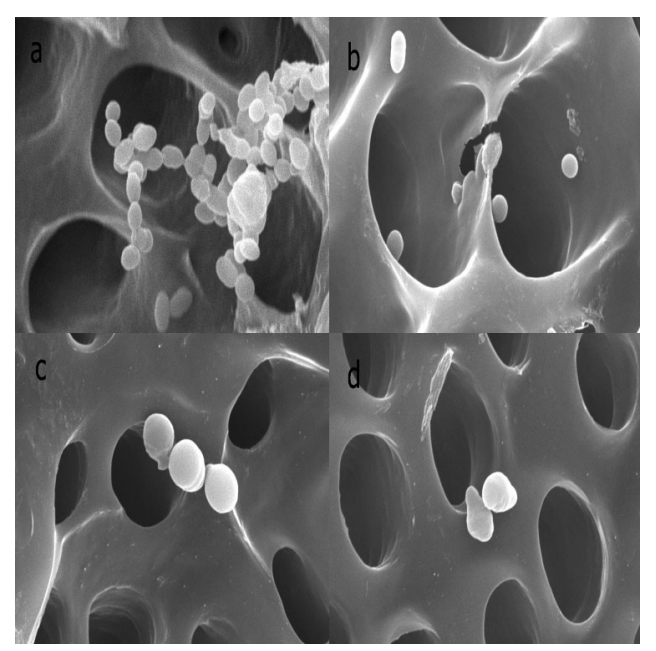

Figure 4. Scanning electron micrograph of Enterococcus faecalis adhered to dentine pieces (10,000X). Exponential phase cells (a), VBNC cells in sterile distilled water (b), VBNC cells in sodium buffer (c and $\mathbf{d})$ with collagen fiber incubated at $37^{\circ} \mathrm{C}$ for $48 \mathrm{~h}$. 


\section{DISCUSSION}

Some species of bacteria enter the VBNC state when they are exposed to adverse environments (Peciuliene et al., 2000; Heim et al., 2002; George et al., 2005). In this state, bacteria lose their ability to form colonies on culture media (Lleò et al., 1998), but remain alive and capable of producing antigen components (Smith and Oliver, 2006) and virulence factors (Pruzzo et al., 2002). When permissive conditions are restored, VBNC cells may resume cell division (Lleò et al., 2001) and participate in disease transmission and persistence (Xu et al., 1982). VBNC E. faecalis cells are viable and can maintain their pathogenicity and other biological functions, such as gene expression (Lleò et al., 2000) and metabolic activity (Lleò et al., 1998). However, there are changes in cell physiology, biochemistry, and genetic characteristics (Oliver, 2005), including changes in morphology, metabolism, and gene expression, that help the bacteria adapt to the adverse environments. Most studies examining the VBNC state of $E$. faecalis have focused on cells in their natural environment and in the intestinal environment. E. faecalis is frequently associated with cases of failed endodontic treatment (Stuart et al., 2006). Therefore, studies on the VBNC state of E. faecalis will lead to a better understanding of treatment failure and suggest possible preventive measures.

Many studies have demonstrated that $E$. faecalis can withstand harsh environmental conditions, including high alkalinity (Sherman, 1937). E. faecalis can grow at $\mathrm{pH} 9.6$ and can tolerate $\mathrm{pH}$ levels as high as 11.9 (Flahaut, 1997). In the RCT process, root canal preparation and clean-up, particularly the typical rinses with $\mathrm{NaClO}$ and $\mathrm{H}_{2} \mathrm{O}_{2}$ and disinfection with $\mathrm{Ca}(\mathrm{OH})_{2}$, make the root canal a high-sodium alkaline oligotrophic environment. In this study, we simulated this unique physical microenvironment and developed 3 in vitro protocols to induce the VBNC state. Sterile distilled water represented an oligotrophic condition, while sodium buffer at $\mathrm{pH} 9$ and 11 represented alkaline environments. All studies were conducted at physiological temperature $\left(37^{\circ} \mathrm{C}\right)$, which was appropriate for bacterial growth. In this study, E. faecalis entered the VBNC state in both the oligotrophic and alkaline microenvironments, and the VBNC cells were able to remain viable for at least 2 months. Approximately 39 and $36 \%$ of E. faecalis survived after culture in sterile distilled water and sodium buffer, $\mathrm{pH} 9$, respectively, for 2 months, while $22 \%$ of cells cultured in sodium buffer, $\mathrm{pH} 11$, remained viable. These results were similar to those obtained in a study by Pruzzo et al. (2002), which focused on the ability of the VBNC E. faecalis cells to adhere to human cells. In that study, E. faecalis entered the VBNC state 16 days after culture in sterilized lake water and $90 \%$ of the bacteria remained alive. Furthermore, approximately one-third of the bacteria were alive after culture for 1 month, which is consistent with our results. In contrast, Heim et al. (2002) reported that $70 \%$ of $E$. faecalis remained 20 days after entry into the VBNC state. This discrepancy may be due to differences in the induction methods used in each study. Changes in the $\mathrm{pH}$ of the microenvironments, particularly increases in $\mathrm{pH}$, may alter the physicochemical characteristics of the bacterial cells and trigger the expression of various genes associated with virulence or metabolic regulation (Olson, 1993). As a result, the bacteria may be able to survive and adapt to the adverse alkaline conditions by entering other physical phases.

E. faecalis is the most common species of Enterococcus. Most cells are arranged in pairs or short chains and they do not form spores or capsules. E. faecalis is catalase-negative and can decompose glucose and maltose into acid. Most strains of E. faecalis are capable of mannitol decomposition and bile aescin glycoside hydrolysis, are vancomycin-sensitive, are slightly alkyl aryl-lactamase-sensitive, are resistant to a range of $\mathrm{pH}$ conditions, and are resis- 
tant to salt and $40 \%$ bile salt. In this study, we used the Rapid ID 32 Strep kit and the ATB Mini API Software to automatically determine how effectively E. faecalis was able to decompose various biochemical substrates, such as lactose, maltose, and mannitol. Compared to exponentially growing cells, VBNC E. faecalis cells lost their ability to decompose lactose, Dmannitol, and D-sorbitol, but retained the ability to decompose most biochemical substrates, including sucrose. Because VBNC E. faecalis were no longer sensitive to certain metabolic substrates, their pathogenicity was decreased, but the carbohydrate metabolism that is retained may still cause harm to host tissues. VBNC E. faecalis produce and release various enzymes and metabolites, which can cause cell toxicity and lead to disintegration of the tissue matrix and spread of the bacteria, or cause indirect tissue damage by inducing an immune response. Enterococcus faecalis exhibits strong resistance to temperature and $\mathrm{pH}$ changes in the external environment, particularly to alkaline environments. The maximum $\mathrm{pH}$ tolerated by $E$. faecalis is 11.6, suggesting a relationship between the alkaline resistance of E. faecalis and its acid production capability. Our experimental observations showed that $E$. faecalis cultured in sterile distilled water decreased the $\mathrm{pH}$ of the culture medium from 8.05 to 6.06 over 1 month of culture; an equivalent drop in $\mathrm{pH}$ was observed in the exponentially growing bacterial culture within $24 \mathrm{~h}$. However, in the sodium buffers, the bacteria reduced the $\mathrm{pH}$ values from initial values of 9.68 and 10.74 to 8.30 and 9.82, respectively, when they entered the VBNC state. These decreases were much smaller than those produced by bacteria in sterile distilled water. However, the reduction in $\mathrm{pH}$ confirmed the acid production ability of VBNC E. faecalis cells. Overall, the VBNC state of E. faecalis was characterized by lower pathogenicity than that of exponentially growing bacteria, as indicated by lower metabolic activity and acid production ability. VBNC cells retained the ability to produce and release several types of metabolites and enzymes and to produce acid, enabling them to maintain their viability and pathogenicity and survive until the external conditions were suitable to support normal growth.

The results of previous studies indicate that when E. faecalis enter the VBNC state, their physiology, biochemistry, and genetic characteristics change (Oliver, 2005), including morphological, metabolism, and genes expression changes. Several studies showed that most Gram-negative bacteria in the VBNC state exhibited a reduced cell volume and a globular morphology. In contrast, VBNC E. faecalis cells increased in size and were slightly elongated (Signoretto et al., 2000). Similarly, in this study, TEM revealed that the average volume of $E$. faecalis in the VBNC state was 1.5-fold larger than that of normal E. faecalis. Furthermore, no previous studies have reported the ultrastructure of VBNC E. faecalis cells. The bacteria observed in our study were irregular in shape because of cytoplasmic condensation. The cytoplasm appeared to be condensed, was darkly and unevenly stained, and contained many vacuoles that formed large gaps between the cell membrane and the cell wall. The granular extracellular secretions were also significantly reduced. These observations indicated that the VBNC state is associated with substantial changes in the cellular ultrastructure of $E$. faecalis. Bacteria may adapt to harsh environments by concentrating their nuclear material and changing their morphology to resist external pressure. Adhesion to the host is the first step in the infection process (Fux et al., 2005). E. faecalis exerts its pathogenicity by adhering to other bacteria, host tissue, or biomaterials and forming a biofilm. It was demonstrated in a previous study that $E$. faecalis in the VBNC state could not form a biofilm, but could still synthesize polymeric substances, thus partially maintaining their adhesion ability and pathogenic potential (Lleò et al., 2007). In this study, we used collagen fiber and dentine pieces collected from extracted teeth to evaluate the adhesion ability of VBNC E. faecalis 
cells in vitro and compared the results with bacteria in the exponential growth phase. These experiments showed that $E$. faecalis incubated in sterile distilled water adhered to collagen and dentine, but bacteria incubated in alkaline sodium buffer exhibited poor adhesion, and only a few bacteria were detected by scanning electron microscopy. It has been reported that adhesion factors on the cell surface, such as 'aggregation substance' and 'Ace', mediate the adhesion of E. faecalis to collagen (Rich et al., 1999; Rozdzinski et al., 2001; Hubble et al., 2003). Significantly, the expression of approximately 200 different proteins was induced in E. faecalis upon exposure to various stressful conditions (Flahaut et al., 1997). The function of these proteins is unknown (Rince et al., 2000; Giard et al., 2001), and additional studies are needed to confirm whether these proteins contribute to bacterial adhesion or resistance against environmental stress.

Bacteria only enter the VBNC state under specific environmental conditions. Previous in vitro VBNC induction protocols have focused mainly on changes in physicochemical conditions, such as temperature, nutrient availability, aeration, and illumination. The influence of these parameters on VBNC state entry is highly variable and depends on the bacterial species. The VBNC state of E. faecalis is typically induced by culture in disinfected filtered lake water as an oligotrophic medium for approximately 15 (Signoretto et al., 2000; Pfeffer et al., 2006) to 30 (Lleò et al., 1998) days with direct illumination at $4^{\circ} \mathrm{C}$. In this study, we simulated the oligotrophic condition using sterilized distilled water and simulated the alkaline environment using sodium buffer at $\mathrm{pH} 9$ and 11. A Live/Dead kit was used to determine the survival rate of the bacteria. This kit utilizes the green-fluorescent nucleic acid stain SYTO9 and the red-fluorescent nucleic acid stain propidium iodide. When used alone, the SYTO9 stain generally labels all bacteria in a population, including those with intact membranes and those with damaged membranes. However, propidium iodide penetrates only bacteria with damaged membranes, reducing SYTO9 fluorescence when both dyes are present. As a result, bacteria with intact cell membranes appear to be fluorescent green and bacteria with damaged membranes appear to be fluorescent red under fluorescence microscopy. Thus, the survival rate of E. faecalis was calculated based on the observed green fluorescence intensity.

In this study, we found that growth glucose metabolism, acid production, and the morphology of $E$. faecalis changed after entry into the VBNC state. We focused primarily on the VBNC state in E. faecalis. However, the mechanism of VBNC entry has not been fully determined, particularly at the level of protein and gene expression. Therefore, additional studies examining the entry and recovery from the VBNC state in E. faecalis are necessary. Moreover, this type of basic research may be used to guide clinical practice. Specifically, analyzing the mechanism underlying the changes that accompany the VBNC state in E. faecalis would be helpful for guiding clinical practice to improve the outcomes of root canal treatment.

\section{Conflicts of interest}

The authors declare no conflict of interest.

\section{ACKNOWLEDGMENTS}

Research supported by the National Natural Science Foundation of China (\#30973321). 


\section{REFERENCES}

Flahaut S, Hartke A, Giard JC and Auffray Y (1997). Alkaline stress response in Enterococcus faecalis: adaptation, cross protection, and changes in protein synthesis. Appl. Environ. Microbiol. 63: 812-814.

Fux CA, Costerton JW, Stewart PS and Stoodley P (2005). Survival strategies of infectious biofilms. Trends Microbiol. 13: 34-40.

George S, Kishen A and Song KP (2005). The role of environmental changes on monospecies biofilm formation on root canal wall by Enterococcus faecalis. J. Endod. 31: 867-872.

Giard JC, Laplace JM, Rincé A, Pichereau V, et al. (2001). The stress proteome of Enterococcus faecalis. Electrophoresis 22: $2947-2954$

Gomes BP, Pinheiro ET, Sousa EL, Jacinto RC, et al. (2006). Enterococcus faecalis in dental root canals detected by culture and by polymerase chain reaction analysis. Oral Surg. Oral Med. Oral Pathol. Oral Radiol. Endod. 102: 247-253.

Heim S, Lleò MM, Bonato B, Guzman CA, et al. (2002). The viable but nonculturable state and starvation are different stress responses of Enterococcus faecalis, as determined by proteome analysis. J. Bacteriol. 184: 6739-6745.

Hubble TS, Hatton JF, Nallapareddy SR, Murray BE, et al. (2003). Influence of Enterococcus faecalis proteases and the collagen-binding protein, Ace, on adhesion to dentin. Oral Microbiol. Immunol. 18: 121-126.

Lleò MM, Tafi MC and Canepari P (1998). Nonculturable Enterococcus faecalis cells are metabolically active and capable of resuming active growth. Syst. Appl. Microbiol. 21: 333-339.

Lleò MM, Pierobon S, Tafi MC, Signoretto C, et al. (2000). mRNA detection by reverse transcription-PCR for monitoring viability over time in an Enterococcus faecalis viable but nonculturable population maintained in a laboratory microcosm. Appl. Environ. Microbiol. 66: 4564-4567.

Lleò MM, Bonato B, Tafi MC, Signoretto C, et al. (2001). Resuscitation rate in different enterococcal species in the viable but nonculturable state. J. Appl. Microbiol. 91: 1095-1102.

Lleò MM, Bonato B, Tafi MC, Caburlotto G, et al. (2007). Adhesion to medical device materials and biofilm formation capability of some species of enterococci in different physiological states. FEMS Microbiol. Lett. 274: 232-237.

Molander A, Reit C, Dahlén G and Kvist T (1998). Microbiological status of root-filled teeth with apical periodontitis. Int. Endod. J. 31: 1-7.

Oliver JD (2005). The viable but nonculturable state in bacteria. J. Microbiol. 43: 93-100.

Olson ER (1993). Influence of pH on bacterial gene expression. Mol. Microbiol. 8: 5-14.

Peciuliene V, Balciuniene I, Eriksen HM and Haapasalo M (2000). Isolation of Enterococcus faecalis in previously rootfilled canals in a Lithuanian population. J. Endod. 26: 593-595.

Pfeffer JM, Strating H, Weadge JT and Clarke AJ (2006). Peptidoglycan O acetylation and autolysin profile of Enterococcus faecalis in the viable but nonculturable state. J. Bacteriol. 188: 902-908.

Pinheiro ET, Gomes BP, Ferraz CC, Teixeira FB, et al. (2003). Evaluation of root canal microorganisms isolated from teeth with endodontic failure and their antimicrobial susceptibility. Oral Microbiol. Immunol. 18: 100-103.

Pruzzo C, Tarsi R, Lleò MM, Signoretto C, et al. (2002). In vitro adhesion to human cells by viable but nonculturable Enterococcus faecalis. Curr. Microbiol. 45: 105-110.

Rich RL, Kreikemeyer B, Owens RT, LaBrenz S, et al. (1999). Ace is a collagen-binding MSCRAMM from Enterococcus faecalis. J. Biol. Chem. 274: 26939-26945.

Rince A, Flahaut S and Auffray Y (2000). Identification of general stress genes in Enterococcus faecalis. Int. J. Food Microbiol. 55: 87-91.

Robbi C, Signoretto C, Boaretti M and Canepari P (1996). The gene encoding for penicillin binding protein 5 of Enterococcus faecalis is useful for development of a species-specific DNA probe. Microbial Drug Resis. 2: 215-218.

Roth BL, Poot M, Yue ST and Millard PJ (1997). Bacterial viability and antibiotic susceptibility testing with SYTOX green nucleic acid stain. Appl. Environ. Microbiol. 63: 2421-2431.

Rozdzinski E, Marre R, Susa M, Wirth R, et al. (2001). Aggregation substance-mediated adherence of Enterococcus faecalis to immobilized extracellular matrix proteins. Microbial Pathog. 30: 211-220.

Sherman JM (1937). The streptococci. Bacteriol. Rev. 1: 3-97.

Signoretto C, Lleò MM, Tafi MC and Canepari P (2000). Cell wall chemical composition of Enterococcus faecalis in the viable but nonculturable state. Appl. Environ. Microbiol. 66: 1953-1959.

Smith B and Oliver JD (2006). In situ and in vitro gene expression by Vibrio vulnificus during entry into, persistence within, and resuscitation from the viable but nonculturable state. Appl. Environ. Microbiol. 72: 1445-1451.

Smith CS, Setchell DJ and Harty FJ (1993). Factors influencing the success of conventional root canal therapy - a five-year retrospective study. Int. Endod. J. 26: 321-333. 
Stuart CH, Schwartz SA, Beeson TJ and Owatz CB (2006). Enterococcus faecalis: its role in root canal treatment failure and current concepts in retreatment. J. Endod. 32: 93-98.

Sundqvist G, Figdor D, Persson S and Sjögren U (1998). Microbiologic analysis of teeth with failed endodontic treatment and the outcome of conservative re-treatment. Oral Surg. Oral Med. Oral Pathol. Oral Radiol. Endod. 85: 86-93.

Xu HS, Roberts N, Singleton FL, Attwell RW, et al. (1982). Survival and viability of nonculturable Escherichia coli and Vibrio cholerae in the estuarine and marine environment. Microb. Ecol. 8: 313-323. 